\title{
Inducible Antimicrobial Compounds (Halal) Production in Honey Bee Larvae (Apis mellifera) from Rumaida, Taif by injecting of various dead Microorganisms extracts
}

\author{
Abd-ElAziem Farouk $^{1 *}$, N. Thoufeek Ahamed ${ }^{1}$, Othman AlZahrani ${ }^{1}$, Akram Alghamdi $^{2}$, AbdulAziz Bahobail $^{2}$ \\ ${ }^{1}$ Molecular Biotechnology Research Unit, Department of Biotechnology, Faculty of Science, Taif University, Al-Hawiya 888, Kingdom of Saudi Arabia. \\ ${ }^{2}$ Department of Biology, Faculty of Science, Taif University, Al-Hawiya 888, Kingdom of Saudi Arabia.
}

\begin{tabular}{l}
\hline ARTICLE INFO \\
\hline Article history: \\
Received on: $08 / 12 / 2016$ \\
Accepted on: $05 / 02 / 2017$ \\
Available online: $20 / 03 / 2017$ \\
\hline Key words: \\
Antibacterial activity, \\
Apis mellifera, honey bee \\
hemolymph, minimum inhibitory \\
concentration, MIC.
\end{tabular}

\begin{abstract}
In the current study, the antimicrobial compounds in induced Honey bee larvae (Apis mellifera) from the Taif region were extracted from hemolymph and assigned as Halal safe product. Their minimum inhibitory concentrations (MIC) were evaluated. Five different microbes, namely Escherichia coli, Bacillus subtilis, Pseudomonas aureus, Candida albicans and Micrococous luteus were used in this study by the agar diffusion assay method. The antibacterial activity of induced honey bee larvae was studied against the 5 above mentioned organisms and the MIC was differentiated from their inhibition for varies microbial growth. The inducible antimicrobial compounds extracted from honey bee larvae hemolymph, after one day at room temperature were used for minimum inhibitory concentration studied. The results showed appreciable antimicrobial activity $(6 \pm 1)$ when the larvae were injected with $15 \mu 1$ Micrococus leutus total protein extract and when injected with the same concentration (i.e. $15 \mu 1$ Pseudomonas aureus), they showed low activity $(4 \pm 1)$ against Candida albicans. The Amoxycillin was used as a standard positive control. The negative control of the Phosphate buffer solvent (PBS) and larvae did not show any activity against all five organisms. All dilutions were executed, minimum inhibitory concentration studies ranging from $10^{-1}$ to $10^{-4}$ did not show any activity. The most inhibition was obtained with induced young larvae at various ages (L4 young larvae and L5- youngest larvae) against Candida albicans.
\end{abstract}

\section{INTRODUCTION}

Honey contains numerous combinations of chemicals of plant and honey bee (Apis mellifera) origin such as sugars, proteins, enzymes, amino acids, vitamins, hormones, flavonoids, inorganic acids, and minerals. The ingredients and the usage of honey were varied subject to their geographical locations, climatic conditions, nature of bee varieties, plant source of the nectar, storage time in honeycomb and the harvesting methods. Honey contains proteins and acids such as Gluconic Acid $\left(\mathrm{C}_{6} \mathrm{H}_{11} \mathrm{O}_{7}\right.$, also known as 2, 3, 4, 5, 6-pentahydroxyhexanoic Acid), minerals and anti-oxidants such as Hydrogen Peroxide and Vitamins B6 and B12 [1]. The well-known antibacterial activity of honey is due to its peroxide-related and non-peroxide-related activity [2]. The presence of variable compounds in honey led to the complexity of specifically defining their antimicrobial activity

* Corresponding Author

E-mail: faroukgad @ gmail.com
[3]. The honey bee (Apis mellifera) is common in Britain, Africa, Europe and the Middle East. It has been introduced to countries in Asia, America and Australia [4] and it belongs to the family Apiidae [5]. The honey bee lacks lymphocytes and immunoglobulin, unlike many other insects, instead they have inducible peptide antibiotics i.e. apidaecins (named from the Apidae, the family of insects to which honeybees belong) found in lymph fluids of the honeybee (Apis melifera). Apidaecins are highly active against Gram negative bacteria. It was reported that three different apidaecins showed comparable activities towards the Escherichia coli [6]. In the honey bee's immune system, the antimicrobial peptides (AMP) are the significant components [7]. Four types of AMP are found in bees: apidaecin present in twelve isoforms [8], abaecin [9], hymenoptaecin [10],) and defensin present in two isoforms $[10,11,12,13]$. AMP is similar to antibiotics and can be used in the development of drugs with antifungal and antibacterial properties [14]. The alcoholic extracts of Eurycoma longifolia (leaves and stem) extracts were active on gram-positive bacteria, reported by Farouk et al [15]. 
Amongst all the AMPs of honey bees, only defensin has cytotoxic activity against fungi; fungus of chalkbrood Ascosphaera apis, fungi of aspergillosis Aspergillus flavus Link and Aspergillus niger Tieghem, yeast-like fungi Candida albicans and Aurobasidium pullulans [16] [17]. Few moths and flies contain bactericidal constituents such as cecropins, attacins, diptericins and insect defensin (sapecin) [18, 19, 20, 21, 22 ]. Certain B. Laterosporus strains exhibited a broad-spectrum antimicrobial activity against various bacteria and fungi. $B$. laterosporus isolated from diseased honey bee larvae affected by European foulbrood (EFB different strains of B. laterosporus), showed a broad spectrum of antimicrobial activity, especially against bacteria and fungi. The same occurrence was observed in B. laterosporus isolated from larvae of the codling moth Cydiapomonella L. (Lepidoptera: Tortricidae), collected from leaves of apple trees in Turkey [23]. The role of extracellular proteases produced by $B$. laterosporus strain G4 in toxicity to nematodes has been confirmed [24]. Eight gram-positive bacterial strains belonging to Lactobacillus spp. (such as Lactobacillus rigidusapis, L. constellatus) and five Enterococcus spp. were isolated from the gut of worker bees (Apis mellifera L.) [25]. Gram-negative bacteria, such as Achromobacter, Citrobacter, Enterobacter, Erwinia, Escherichia coli, Flavobacterium, Klebsiella, Proteus and Pseudomonas, and yeasts were present in Apis mellifera L. bees [26, 27, 28, 29,30].

Quantitative analysis of honey bee larvae infected with the bacterium Paenibacillus larvae showed an elevated expression of immunity proteins, chaperones, certain metabolic proteins with an accelerated consumption of energy stores [31].

Honey bee larvae collected nectar primarily from flowers in Rumaida, Taif. The extracts of flowers of $R$. damacena cv. Taifi showed antimicrobial activity, reported by Farouk et al. [32] .

During metamorphosis, all of the honey bees experienced dissimilar growing stages (egg, larvae, pupa, and adult). Drones have an extended development period (24 days), workers are intermediate (21 days), and queens are the fastest (15-16 days).

Honey bee larvae, grub-like immature form of the honey bee after it has developed from the egg and before it has gone to the pupa stage, were used for this study. Although the average number of days a worker bee needs to complete all development stages from egg to adult takes 21 days, it remains as an egg for the initial 3 days. The next 6 days they are found in the larva stage. Then in the pupa will be reach its stage for 12 days. Both the young (L4) and the youngest larvae (L5) were used for the induction. The larval growth difference is wider than the embryo's growth in other organisms. I.e. instead of growing by cell division, the larvae grow larger expansion of their cells. The curled larvae (round larvae) at the bottom of the cell in the comb were taken before their $9^{\text {th }}$ day for the study. The nectar (the sweet fluid produced by flowers containing $60 \%$ water and $40 \%$ solids), collected by larvae's of different ages and matured bees were taken for the present study on "Inducible Antimicrobial Compound Production in Honey Bee Larvae (Apis mellifera) from Rumaida, Taif by injecting of various dead Microorganism extracts". The immune system in the honeybee, Apis mellifera $L$ larvae of different stages was induced by different microbes (Bacillus subtilis, Escherichia coli, Pseudomonas auerus, Candida albicans and Micrococous leutus) for the production of AMP or the antimicrobial compounds. It is known that honey bee larvae have antimicrobial effects [32].

In this study, these honey bee larvae and adults were assayed for the antibacterial activity and were compared with standard commercialized antibiotic, Amoxycillin, as positive control.

\section{MATERIALS AND METHODS}

\subsection{Chemicals}

Chemicals were purchased from Sigma-Aldrich Chemical Co., (St. Louis, Mo, USA) and Himedia, Mumbai, India. Ethanol was purchased from BHD (Poole, UK-Fluka Chemical, Buchs, Switzerland). All chemicals and reagents had an analytical grade.

\subsection{Media}

Nutrient agar and nutrient broth were used to culture five different microbial species. The nutrient agar was used to isolate colonies and to observe the zone of inhibition around sterile agar plates. The nutrient broth was used in making liquid cultures from isolated colonies from the agar plates. The liquid cultures which were grown in the orbital shaker at $100 \mathrm{rpm}$ and $37^{\circ} \mathrm{C}$ for $24 \mathrm{hrs}$ were then used in the agar plates diffusion assay, the serial dilutions were in the range of $10^{-1}$ to $10^{-4}$. The fresh saline Phosphate Buffer Solvent (PBS), prepared by dissolving $\mathrm{NaCl}$ $(8 \mathrm{~g}) ; \mathrm{KCl}(0.2 \mathrm{~g}) ; \mathrm{Na}_{2} \mathrm{H}_{2}(1.42 \mathrm{~g})$ and $\mathrm{KH}_{2} \mathrm{PO}_{4}(0.4 \mathrm{~g})$ in one liter of distilled water, was sterilized in an autoclave before usage.

\subsection{Bacteria/Fungi}

Five different species of bacteria, namely: Escherichia coli ATCC 25922 (gram-negative), Bacillus subtilis ATCC 6633 (gram- positive), Pseudomonas aureus ATCC27853 (gramnegative), and fungi Candida albicans ATCC 10231 and Micrococus leutus ATCC 9341(gram-positive) were used in this study to explore the effectiveness of both adult and honey bee Apis amellifera larvae on the inhibition of growth; the bacteria chosen for this study were both gram-positive and gram-negative Bacteria.

\subsection{Culture Preparation}

Six $50 \mathrm{ml}$ bottles, each containing $25 \mathrm{ml}$ of nutrient broth, were inoculated separately with five microorganisms (Escherichia coli, Bacillus subtilis, Pseudomonas aureus, Candida albicans and Micrococous leutus) using an inoculums loop in sterile conditions. The nutrient broth solutions which were inoculated were then incubated at $37^{\circ} \mathrm{C}$ for up to 24 hours.

\subsection{Honey bee larvae /Adult bee}

During the winter seasons of 2015/2016, the honey bee larvae, pupae and /adult bee Apis mellifera were collected from the 
Taif area. The nectar was gathered with the larvaes of different stages (i.e. ages from 3 days up to 8 days) and matured bees (21 days). Both larvae and adults were used for the present study.

\subsection{Artificial infection of larvae and adults:}

The hatched larvae, after 3 days of egging, were collected from honey combs with a Swiss grafting tool and transferred into a $1.5 \mathrm{ml}$ tube with a basic PBS in it. $(600 \mu \mathrm{l})$. The honey bee larvae and an adult bee were injected dorsally with 10 $\mu \mathrm{l}$ of dead bacterial and fungal extracts from five different microorganisms. For injection, a disposable calibrated $(0.1-0.5$ ml) sterile plastic injector (BD Micro-fine Plus, USA) was used. The Adult bee and larvae were injected laterally between the second and third tergum of the abdomen. The grafted larvae and bee were kept at $30^{\circ} \mathrm{C}$ and $70 \%$ relative humidity for one day. For each series of experiments, the collected bee's hemolymph was divided into groups of 3 individuals and kept in separate tubes named as L1, L2, L3, L4 and L5. After one day at room temperature, all the tubes were individually mixed thoroughly in a vortex mixer (Labnet). Afterwards, they were warmed for 2 minutes in a Branson Ultrasonic cleaner (1510). They were then kept at $-80^{\circ} \mathrm{C}$ for 5 minutes, followed by a heat treatment at $42^{\circ} \mathrm{C}$ for 5 minutes in a water bath. The process of temperature shocks was repeated one more time. The tubes were centrifuged in MIKRO 120 instrument at 13,000 rpm for 5 minutes. Transferred $50 \mu 1$, the filtrate in ager well for the antimicrobial study were applied.

Note: For the serial dilution of honey bee larvae preparation, the larvae were injected dorsally with $15 \mu \mathrm{l}$ of each dead bacterial and fungal extracts from five different microorganisms.

\subsection{Serial dilutions of honey bee larvae hemolymph extract preparation}

In this serial dilution or dilution series of honey bee larvae, a series of successive dilutions were used to diminish a thick culture of cells to a more practical concentration. The concentration of bacteria or fungi in each dilution was lessened by a precise amount. So, by calculating the total dilution over the entire series, it was possible to know with which amount bacteria one can begin with. The same dilution factor, with the diluted material from the previous step, was used to make the subsequent dilution. When executing very high dilutions (like $1 / 10,000$ or $1 / 1,000,000)$, it was more accurate to do the dilution in a series of smaller dilutions rather than in one giant dilution. Hundred microliters $(100 \mu \mathrm{l})$ of the original honey bee larvae culture (labeled as U.S. -Undiluted solution) was measured initially. Before starting the dilution process, several dilution blanks, which were tubes containing diluting liquid (sterile water) in exact quantities, were prepared. Four dilution blanks in $1.5 \mathrm{ml}$ microcentrifuge tubes (Eppendorf tubes), were numbered 1 to 4 . In each tube, exactly $900 \mu \mathrm{l}$ of liquid media was taken. By gently shaking the tube initially, the honey bee cells were evenly distributed in the tube to avoid the threat of not getting adequate cells.

Step 1: Exactly $100 \mu \mathrm{l}$ from U.S. tube was transferred to tube 1 , making it $1 \mathrm{ml}$ of liquid in tube 1 . I.e. exactly one-tenth of honey bee larvae cells were in a new tube with a final volume of 1 ml. ( 1 in 10 dilution, or it could be written as $1 / 10$ or $10^{-1}$ ) where 1 is the volume transferred, and 10 was the final volume of the tube after the transfer.

Step 2: Tube 1 became the next tube to be diluted. After swirling tube $1,100 \mu \mathrm{l}$ was transferred from tube 1 into tube 2 . Again, exactly one-tenth of honey bee larvae hemolymph in tube 1 were transferred into tube 2, with a final volume of $1 \mathrm{ml}$. Exactly 9 $\mathrm{ml}$ was then remaining in tube 1 . Tube 2 now contained a 1 in 10 dilution of tube 1 . To calculate the total dilution from tube U.S. (undiluted solution), we simply multiplied the two dilutions: 1/10 $\mathrm{X} 1 / 10=1 / 100$. So far, we have performed a $1 / 100$ dilution from the original honey bee larvae culture.

Step 3 and Step 4: The same procedure for the remaining dilution blanks was followed: $100 \mu \mathrm{l}$ from tube 2 was transferred into tube 3; finally, $100 \mu \mathrm{l}$ from tube 3 was transferred to tube 4 , each transfer was another 1 in 10 dilution. The final dilution was calculated by simply multiplying all the dilutions together: $1 / 10 \times 1 / 10 \times 1 / 10 \times 1 / 10=1 / 10,000$ or $10^{-4}$

A single dilution was normally calculated as follows:

Dilution =

volume of the sample

Total volume of the sample + diluents volume

For example the dilution of $1 \mathrm{ml}$ into $9 \mathrm{ml}$ equals:

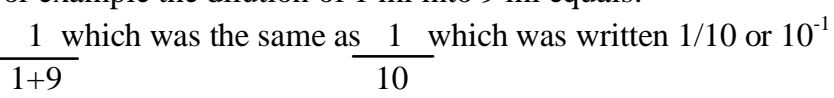

Amoxycillin Preparation:

$500 \mathrm{mg}$ of Amoxycillin was dissolved in $100 \mathrm{ml}$ water and alcohol (50:50 mixtures) was considered as the undiluted solution (U.S). Serial dilutions were made from this U.S from $10^{-1}$ to $10^{-4}$

\subsection{Detection of the Minimum Inhibitory Concentration (MIC)}

The minimum inhibitory concentration was the lowermost concentration of an antimicrobial that will hinder the visible development of a microorganism after overnight incubation. This concentration endorses the resistance of microorganisms to an antimicrobial agent and also to decide the potency of new antimicrobial agents [33, 34]. Minimum inhibitory concentrations (MICs) can be used in selecting the best antimicrobial agent with known culture.

\subsection{Experimental Methods}

The nutrient agar plates were made by weighing 28 grams of nutrient agar (obtained from Himedia, India) and dissolving it in one liter of sterilized distilled water. The solution 
was autoclaved after adjusting the $\mathrm{pH}$ to 7.4 for 20 minutes at $15 \mathrm{psi}$ $(1.05 \mathrm{~kg} / \mathrm{cm})$ and at $121^{\circ} \mathrm{C}$ on liquid cycle. The autoclaved medium was swirled gently to distribute the melted agar evenly throughout the solution and was then allowed to cool to between 50 to $60^{\circ} \mathrm{C}$. Then under sterile conditions, $20 \mathrm{ml}$ of this medium was poured onto $90 \mathrm{~mm}$ Petri dishes and was set to cool. When the medium set completely, Petri dishes were inverted and stored at $4^{\circ} \mathrm{C}$, they were taken out from storage 2 hours earlier to use [35].

The suspensions of the 5 microbial cultures were covered completely on the agar plates and were allowed to dry. Note 1: The bacterial strains used were Bacillus subtilis ATCC 6633, Candida albicans ATCC 10231; Escherichia coli ATCC 8739; Micrococcus luteus ATCC 9341 and Pseudomonas aeruginosa ATCC27853 (ATCC: American Type Culture Collection). The five strains were maintained on nutrient agar and freshly prepared sub-cultures in nutrient broth. This was done by transferring two or three colonies (from the old parent glycerol culture of 5 microorganisms) into a bottle containing $20 \mathrm{ml}$ of liquid nutrient broth medium and were left to grow for 24 hours (or overnight) at $37^{\circ} \mathrm{C}$, a small aliquot was poured on plates and dried.

The standard agar-well diffusion method [36] was employed to determine the antimicrobial activities for both larvae and adult honey bee protein extracts. This method is normally vital for all types of susceptibility testing. The size of inoculums, contents and acidity of the growth medium, as well as time and temperature of incubation normally affect the results. Also, the agar depth, diffusion rate of the antimicrobial agent and growth rate of the specific bacteria should be considered. The holes $(6 \mathrm{~mm})$ were made in agar using sterile yellow tip and $50 \mu \mathrm{l}$ of the test extract solution was used for the five microorganisms. These bacteria cultures were then stored at $4{ }^{\circ} \mathrm{C}$. A positive (solvent) and larvae was also used as the control. All test solutions were added inside the laminar flow cabinet. Allowing solutions in the wells to diffuse for 15-20 minutes, the plates were then incubated for 24 hours at $37^{\circ} \mathrm{C}$. After incubation, clear areas in the region of the wells containing antimicrobial compounds appeared. This diameter of the clear area (called the inhibition zones) around the wells were measured and recorded. Antimicrobial activities of each larvae group and the adult honey bee extracts were expressed in terms of average diameter of the inhibition zone (evaluated in milliliter). Other larvae group's extracts were tested in the same manner. The concentrations of the extract used and the inhibition zones values that give the optimum result were identified.

In case of serial dilution, the larvae were injected dorsally with $15 \mu \mathrm{l}$ of dead bacterial and fungal extracts from five different microorganisms.

\section{RESULTS AND DISCUSSION}

The inducible antimicrobial compounds extracted from honey bee larvae/adult (Apis mellifera) and their anti-microbial activities against all the five extracts obtained from Gram positive bacteria (Bacillus subtilis, Micrococcus luteus), Gram negative bacteria (Escherichia coli, Pseudomonas aeruginosa) and fungi
(Candida albicans) were examined (as shown in Table 1) by the standard agar well diffusion clearing zone method. The results after 10 days were also stated in Table 2.

Table 1: The protein extract $(50 \mu 1)$ of honey bee Larvae and adult honey bee injected with extract $(10 \mu \mathrm{l})$ of five dead microorganisms against selected microorganisms in nutrient agar plates.

\begin{tabular}{|c|c|c|c|c|c|}
\hline \multirow[b]{2}{*}{$\begin{array}{c}\text { Name of organisam } \\
\text { injected with } 10 \mu \mathrm{l} \\
\text { (Larvae-3Nos)/Honey bee } \\
\text { Extract used : } 50 \mu \mathrm{l}\end{array}$} & \multicolumn{5}{|c|}{$\begin{array}{l}\text { Inhibition zones in individual agar } \\
\text { plates containing five } \\
\text { different micro organisms }(\mathrm{mm})\end{array}$} \\
\hline & 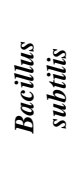 & 胥 & 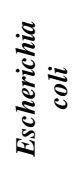 & 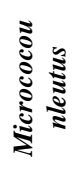 & 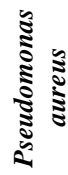 \\
\hline PBS+Lar & Nil & Nil & Nil & Nil & Nil \\
\hline Bacillus subtilis + Larvae. & Nil & Nil & $17 \pm 1$ & Nil & Nil \\
\hline Candida albicans+Larvae. & Nil & Nil & Nil & Nil & Nil \\
\hline Escherichia coli+Larvae. & Nil & Nil & $13 \pm 1$ & Nil & Nil \\
\hline Micrococous leutus+Larvae. & Nil & $4 \pm 1$ & $11 \pm 1$ & Nil & Nil \\
\hline Pseudomonas aureus+Larvae. & $14 \pm 1$ & Nil & Nil & Nil & Nil \\
\hline PBS +Honey bee. & Nil & Nil & Nil & Nil & Nil \\
\hline Bacillus subtilis +Honey bee. & Nil & $8 \pm 1$ & $7 \pm 1$ & Nil & Nil \\
\hline Candida albicans + Honey bee. & Nil & $8 \pm 1$ & $9 \pm 1$ & Nil & Nil \\
\hline
\end{tabular}

Table 2: The total hemolymph extract $(50 \mu 1)$ of honey bee Larvae and adult honey bee injected with extract $(10 \mu \mathrm{l})$ of five dead microorganisms after 10 days against selected microrganisms in nutrient agar plates.

\begin{tabular}{|c|c|c|c|c|c|}
\hline \multirow{2}{*}{$\begin{array}{c}\text { Name of microorganism } \\
\text { injected with } 10 \\
\mu \mathrm{l}(\text { Larvae3Nos)/Honey bee } \\
\text { Extract used : } 50 \mu \mathrm{l}\end{array}$} & \multicolumn{5}{|c|}{$\begin{array}{l}\text { Inhibition zones in individual agar } \\
\text { plates containing five } \\
\text { different microorganisms ( } \mathrm{mm})\end{array}$} \\
\hline & 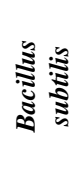 & 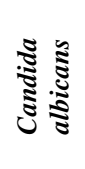 & 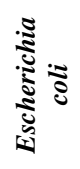 & 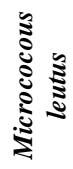 & 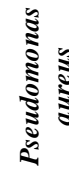 \\
\hline PBS & Nil & Nil & Nil & Nil & Nil \\
\hline Bacillus subtilis + Larvae. & Nil & Nil & $12 \pm 1$ & Nil & Nil \\
\hline Candida albicans + Larvae. & Nil & Nil & Nil & Nil & Nil \\
\hline Escherichia coli + Larvae. & Nil & Nil & Nil & Nil & Nil \\
\hline Micrococous leutus + Larvae. & Nil & Nil & $12 \pm 1$ & Nil & Nil \\
\hline Pseudomonas aureus + Larvae & Nil & $1 \pm 1$ & $11 \pm 1$ & Nil & Nil \\
\hline PBS + Honey bee & Nil & Nil & Nil & Nil & Nil \\
\hline Bacillus subtilis + Honey bee. & Nil & $3 \pm 1$ & $6 \pm 1$ & Nil & Nil \\
\hline Candida albicans + Honey bee. & Nil & $2 \pm 1$ & $8 \pm 1$ & Nil & Nil \\
\hline
\end{tabular}

In our study the antimicrobial activities of honey bee larvae at different growth stages and adult bee exhibited varying results against the five different microorganisms (as shown in Table 1). The serial dilution method was applied for the larvae of different ages and the results were showed in Table 3 . The honey bee larvae, (three in a group in a sealed tube) and adult bee were injected with an extract of $10 \mu \mathrm{l}$ each of all five different microorganisms in 5 separate tubes. A total of 15 larvae were taken for the study. The protein extracts that were used against the five microorganisms smeared in nutrient agar plates which were dried. The inhibition zones showed good results against Candida

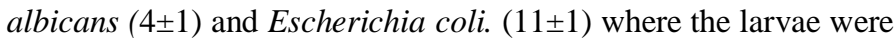
injected with10 $\mu 1$ Micrococus leutus. The inhibition zones showed higher value results against Escherichia coli (13 \pm 1$)$ where the larvae were injected with $10 \mu \mathrm{l}$ Escherichia coli. The other three groups of larvae (three each), that were injected with Bacillus subtilis, Pseudomonas aureus and Candida albicans did not show 
any activity against their own counter parts (as shown in Table 1). The positive control of larvae hemolymph extract in PBS alone did not show any activity against all of the five microorganisms. The total hemolymph extract $(50 \mu \mathrm{l})$ of honey bee Larvae and adult honey bee injected with extract $(10 \mu \mathrm{l})$ of five dead microorganisms after 10 days against selected microrganisms in nutrient agar plates were observed (as shown in Table 2). The inhibition zones showed reduced results against Bacillus subtilis + Honey bee $(3 \pm 1)$ and Candida albicans + Honey bee $(2 \pm 1)$. The prolonged unfavorable extended environment has negative impact with adult bee and the selected honey bee larvae showed no signs of life within 24hours. The inhibition zones showed higher value results against Escherichia coli $(12 \pm 1)$ where the larvae were injected with $10 \mu \mathrm{l}$ either Micrococous leutus or Bacillus subtilis. When the honey bee larvae, three in a group, were injected with an extract of $15 \mu \mathrm{l}$ Bacillus subtilis or $15 \mu 1$ Micrococus leutus or $15 \mu 1$ Pseudomonas aureus and kept at room temperature. After one day, the larvae were smashed out and the extracted proteins were used for minimum inhibitory concentration (MIC) studies. It showed no antimicrobial activity against Escherichia coli (as shown in Table 3 ) at varying diluted concentrations from $10^{-1}$ to $10^{-4}$. But at the higher original undiluted concentration, denoted as U.S, the inducible antimicrobial protein/compounds extracted from honey bee larvae showed appreciable activity $(6 \pm 1)$ (as shown in Table 3 ) when the larvae were injected with $15 \mu$ l Micrococus leutus (L4) and kept at room temperature. After one day, the larvae were smashed out and the extracted total hemolymph was used for minimum inhibitory concentration (MIC) studies against Candida albicans.

Table 3: The total hemolymph extract $(50 \mu \mathrm{l})$ of honey bee Larvae injected with extract $(10 \mu \mathrm{l})$ of five dead Microorganisms against selected three microorganisms in Nutrient agar plates.

\begin{tabular}{|c|c|c|c|}
\hline $\begin{array}{c}\text { Honey bee larvae } \\
\text { dilution } \\
\text { Concentrations }\end{array}$ & $\begin{array}{c}\text { Name of } \\
\text { organism } \\
\text { injected : } 15 \mu \mathrm{l}) \\
\text { (Larvae-3 Nos) }\end{array}$ & $\begin{array}{c}\text { Candida } \\
\text { albicans } \\
\text { (L4 and } \\
\text { L5) }\end{array}$ & $\begin{array}{l}\text { Escherichia } \\
\text { coli } \\
\quad \text { (L1) }\end{array}$ \\
\hline $10^{-1}$ & \multirow{5}{*}{$\begin{array}{l}\text { Micrococous } \\
\quad \text { leutus }\end{array}$} & Nil & \multirow{15}{*}{ Nil } \\
\hline $10^{-2}$ & & Nil & \\
\hline $10^{-3}$ & & Nil & \\
\hline $10^{-4}$ & & Nil & \\
\hline U.S & & $6 \pm 1$ & \\
\hline $10^{-1}$ & \multirow{5}{*}{$\begin{array}{c}\text { Pseudomonas } \\
\text { aureus }\end{array}$} & Nil & \\
\hline $10^{-2}$ & & Nil & \\
\hline $10^{-3}$ & & Nil & \\
\hline $10^{-4}$ & & Nil & \\
\hline U.S & & $4 \pm 1$ & \\
\hline $10^{-1}$ & \multirow{5}{*}{ Bacillus subtilis. } & Nil & \\
\hline $10^{-2}$ & & & \\
\hline $10^{-3}$ & & & \\
\hline $10^{-4}$ & & & \\
\hline$U . S$ & & & \\
\hline $10^{-1}$ & \multirow[t]{5}{*}{ Amoxycillin } & $7 \pm 1$ & $7 \pm 1$ \\
\hline $10^{-2}$ & & $6 \pm 1$ & $6 \pm 1$ \\
\hline $10^{-3}$ & & $1 \pm 1$ & $4 \pm 1$ \\
\hline $10^{-4}$ & & Nil & $2 \pm 1$ \\
\hline U.S & & $9 \pm 1$ & $9 \pm 1$ \\
\hline
\end{tabular}

Pipette $50 \mu \mathrm{l}$ of the concentrated (undiluted) total hemolymph extract in agar wells only showed antimicrobial activity. The varied diluted concentrations from $10^{-1}$ to $10^{-4}$ did not show any activity (as shown in Fig.1).
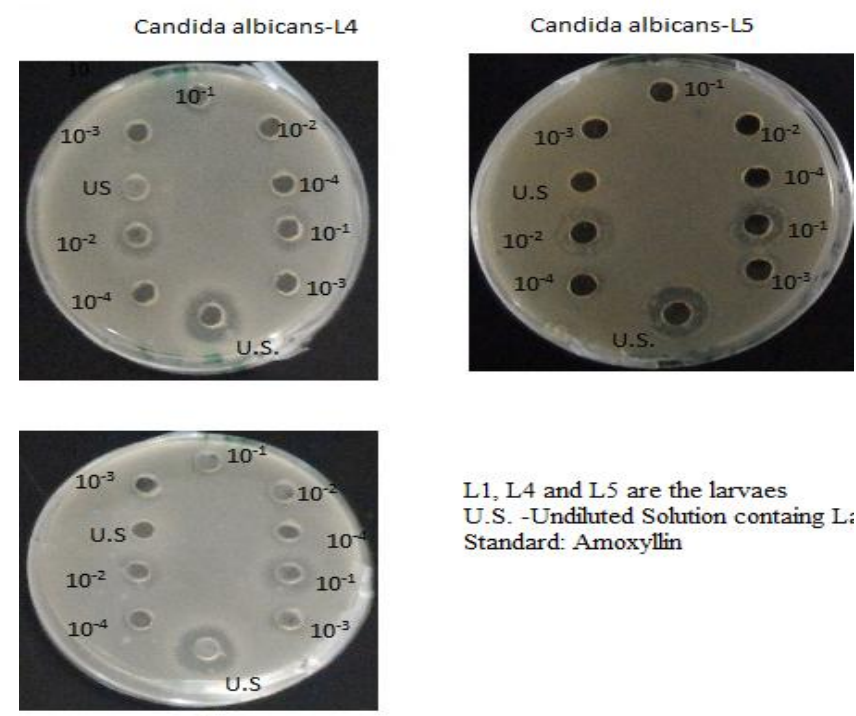

L1, L4 and L5 are the larvaes U.S. -Undiluted Solution containg L: Standard: Amoxyllin

Eschersia.coli-L1

Fig. 1: The total hemolymph extract $(50 \mu \mathrm{l})$ of honey bee larvae injected with extract $(15 \mu \mathrm{l})$ of five dead microorganisms against Candida albicans and $E$. coli in nutrient agar plates to study the minimal inhibitory concentration. Inhibition zones were designed in individual Plates corresponding to their serial dilution factors from $10^{-1}$ to $10^{-4}$.

Also, at the higher original undiluted concentration, the inducible antimicrobial compounds that were extracted from honey bee larvae hemolymph showed a weaker activity $(4 \pm 1)$ (as shown in Table 3) when the larvae was injected with $15 \mu \mathrm{l}$ Pseudomonas aureus(L5) and after one day at room temperature, the larvae was smashed out and all the extracted hemolymph was used for minimum inhibitory concentration (MIC) studies against Candida albicans than the larvae was injected with same concentration i.e. $15 \mu \mathrm{l}$ Micrococus leutus. Pipetted $50 \mu \mathrm{l}$ of the concentrated (undiluted) total hemolymph extracts in agar wells showed antimicrobial activity. The diluted concentrations from 10 ${ }^{-1}$ to $10^{-4}$ did not show any activity (as shown in Fig.1), similar to the larvae injected with Micrococus leutus.

The higher the concentration (named L4), i.e. the $1.5 \mathrm{ml}$ tube containing larvae and $15 \mu \mathrm{l}$ Micrococus leutus and L5, the 1.5 tube containing larvae and $15 \mu \mathrm{l}$ Pseudomonas aureus, containing the inducible antimicrobial compounds which were extracted from the honey bee larvae hemolymph, showed a higher activity than the other varying diluted lower concentrations.

The degree of antibacterial activity varied according to the type of bacteria selected. The minimum inhibitory concentration (MIC) has been observed to lie around $(50 \mu \mathrm{l} / 600 \mu \mathrm{l}$ PBS), i.e. $8 \%$ against $\mathrm{CA}$ used in this investigation. The inducible antimicrobial compounds extracted from honey bee larvae extracts had no activity against $E$ coli. These results comply with other reported research outcomes, that the low dilution of alcoholic extract Eurycoma longifolia Jack showed a higher microbial 
activity as compared to high dilution [37] and also native isolated bacteria from sea cucumber recorded moderate antimicrobial activity against $P$. aeruginosa [38]. In case of honey, $20 \%$ was sufficient to inhibit the growth of a range of isolates. The results obtained in our study were in agreement with the predictable range of MIC for honey between 5-10 \% [39] and MIC of 30-50 \%. [40].

\section{CONCLUSION}

In this study, the inducible antimicrobial compounds extracted from honey bee larvae hemolymph were more sensitive against the fungus Candida albicans than gram-negative bacteria when injected with either Micrococus leutus or Pseudomonas aureus. These results were positive and promising due to the fact that the honey bee larvae is considered to be rich with antimicrobial sources; therefore, further studies should be carried out to confirm the purification of the antimicrobial compounds. 9 days after hatching from its egg, the larvae cell was capped with wax by worker bees and for another 12 days, the larva pupates and undergoes miraculous metamorphosis. During this time, the release of antimicrobial compounds by inducing the same or other microorganisms can be studied for further information. It was clear from this study that honey bee larvae of different stages acted differently. This was to be expected since the age of each honey bee larvae was different and the injected selected different dead microbial extracts used. Also, the antimicrobial compounds produced could be varied for different stages of honey bee larvae according to the different floral sources of honey in which they grow or the particular species of the bee (African or Middle East). An extensive study is further required. The results provided ground information for the potential use of the extracts of induced honey bee larvae. It is also concluded that the MIC concentration of extract of induced honey bee larvae hemolymph and the data proved that honey bee larvae has curative values.

\subsection{Conflict of Interests}

The authors declare that there is no conflict of interests regarding the publication of this paper.

\section{ACKNOWLEDGEMENT}

The authors express their gratitude to Taif University, for their Grant 928/431/1, Al-Hawiya 888, Kingdom of Saudi Arabia, Deputy President for postgraduates and Research Prof. Dr. Saad Alzahrani and the support of the Dean of Science. Also, the authors extend their sincere gratitude for the support of the Biotechnology \& Biology Department of Taif University, Saudi Arabia for its financial support for these research efforts.

Conflict of Interests: There are no conflicts of interest.

\section{REFERENCES}

1. Yates BD, Yates JD. Beekeeping study notes for the BBKA examination: Modules 1,2,3 and 4. vol. 1, 1996. Bee Books New and Old.
2. Molan PC, Russell KM. Non-peroxide antibacterial activity in some New Zealand honeys. J Apic Res. 1988; 27: 62-67.

3. Peter BO, Olufemi EA, Iyab. Honey: a reservoir for microorganisms and an inhibitory agent for microbes. African Health Sciences 2007; 7(3): 159-165.

4. Thompson GJ, Oldroyd, BP. Evaluating alternative hypotheses for the origin of eusociality in corbiculate bees. Molecular Phylogenetics \& Evolution. 2004; 33: 452-456.

5. Winston ML. Killer Bees: The Africanized Honey Bee in the Americas. Harvard Univ. Press, Cambridge, Massachutes, USA. 1992; 176.

6. Peter C, Christophe A, Frans J, Mark V and Paul T. Apidaecins: antibacterial peptides from honeybees. The Embryo. 1989; 8(8): 2387-2391.

7. Hoffmann JA, Kafatos FC, Janawey CA, Ezekovitz RAB. Phylogenetic perspectives in innate immunity. Science. 1999; 284: 1313-1318.

8. Casteels P, Ampe C, Jacobs F, Vaek M, Tempst P. - Apidaecins: antibacterial peptides from honey bees. The EMBO. (1989); 8: $2387-$ 2391.

9. Casteels P, Ampe C, Riviere L,Damme JV, Elicone C, Fleming M, Jacobs F, Tempst P. 1990. Isolation and characterization of abaecin, a major antibacterial peptide in the honey bees (Apis mellifera). Eur. J. Biochem. v. 187, p. 381-386.

10. Casteels P, Ampe C, Jacobs F, Tempst P. Functional and chemical characterization of hymenoptaecin, an antibacterial polypeptide that is infection inducible in the honey bees (Apis mellifera). J.Biol. Chem. 1993; 268: 7044-7054.

11. Ilyasov RA, Gaifullina LR, Saltykova ES, Poskryakov AV and Nikolaenko AG. Defensins in the Honeybee Antiinfectious Protection. Journal of evolutionary biochemistry and physiology. 2013; 49 (1).

12. Casteels-josson K, Zhang W, Capaci T, Casteels P, Tempst P. Acute transcriptional response of the honey bee's peptide-antibiotics gene repertoire, required posttranslational conversion of the precursor structures. J. Biol. Chem. 1994; 269: 28569-28575.

13. Gilliam M, Prest DB. Microbiology of feces of the larval honey bee, Apis mellifera. Jinvert Pathol. 1987; 49: 70-5.

14. Bulet P, Hetru C, Dimarcq JL, Hoffmann D. Antimicrobial peptides in insects; structure and function. DeComposition Immunology. 1999; 23: 329-344.

15. Farouk A, Nawi M, Hassan S. Antibacterial peptides from Euycoma longifolia (Tongkat Ali) and Labisia pumila (Kacip Fatimah) leaves in Malaysia. Sci. Brun. 2008; 9: 55-63.

16. Chernysh SI, Gordya NA, Filatova NA. Sacrificial mechanisms of insects: the rate of molecular and phenotypic evolution. Genetics Research. 1999; 12: 52-59.

17. Aronstein KA, Murray KD. Chalkbrood disease in honey bees. Journal of Invertebrate Pathology. 2010; 103: 20-29.

18. Dunn PE. Biochemical aspects of insect immunology. Annu. Rev. Entomol. 1986; 31: 321-339.

19. Boman and Hultmark, Boman, HG and Hultmark D. Cell-Free Immunity in Insects. Annu. Rev. Microbiol. 1987; 41: 103-126.

20. Dimarcq JL, Keppi E, Dunbar B, Lambert J, Reichhart JM, Hoffmann D, Rankine, SM, Fothergill JE, Hoffmann JA. Eur. J. Biochem. 1988; 171: 17-22.

21. Matsuyama $\mathrm{K}$ and Natori K. Purification and Characterization of $N$ $\beta$-Alanyl-5-S-glutathionyl-3,4-dihydroxyphenylalanine, a Novel Antibacterial Substance of Sarcophag aperegrina (Flesh Fly) J. Biol. Chem. 1988; 263: 17112-17116.

22. Lambert J, Keppi E, Dimarcq JL, Wicker C, Reichhart JM, Dunbar B, Lepage P, Van Dorsselaer A, Hoffmann J, Fothergill J.and Hoffmann D. Insect immunity: isolation from immune blood of the dipteran Phormiaterranovae of two insect antibacterial peptides with sequence homology to rabbit lung macrophage bactericidal peptides. Proc. Natl. Acad. Sci. USA. 1989; 86: 262-266.

23. The Ministry of Agriculture of Turkey, The Technical Guide of Agricultural Control, T.C. Ankara, Turkey. 1995; 5: 117-121. 
24. Huang, Tian B, Niu Q, Yang J, Zhang L, Zhang K. An extracellular protease from Brevibacillus laterosporus G4 without parasporal crystals can serve as a pathogenic factor in infection of nematodes Res Microbiol. 2005; 156 (5-6): 719-27.

25. Carina Audisioa M, María JT, Daniela CS, Carolina I, María CA. Properties of different lactic acid bacteria isolated from Apis mellifera L. Bee-gut. Microbiological Researc. 2011; 166: 1-13.

26. Rousseau M, Tysset C, Durand C. Presence of streptococci of the Lancefield D group in healthy working bees (Alpis mellifica L.). Interpretation of their presence in alimen-tary bacteriology. Bull Acad Vet Fr. 1969; 42: 173-8.

27. Gilliam M, Morton HL. Bacteria belonging to the genus Bacillus isolated from honey bees, Apis mellifera, fed 2, 4-D and antibiotics. Apidologie. 1978; 9: 213-22.

28. Rada V, Ma chova M, Huk J, Marounek M, Duskova B. Microflora in the honey bee digestive tract: count, characteristics and sensitivity to veterinary drugs. Apidologie. 1997; 28: 357-65.

29. Mohr KI, Tebbe C. Diversity and phylotype consistency of a certain the guts of three bee species (Apoidea) at an oil seed rape field. EnvironMicrobiol. 2006; 8: 258-72.

30. Queenie WT Chan, Andony PM, Stephen FP and Leonard JF. The innate immune and systemic response in honey bees to a bacterial pathogen, Paenibacillus larvae. BMC Genomics. 2009; 10: 387, p. 19.

31. Farouk A, Banaja A, Thoufeek AN, Alzahrani O, Bazaid S. Afr. J. Micrbiol. Res. 2014; 8(50) : 3913-3917.

32. Carmelina FM, Jack BS, Daniel P, Peter B. Chemical composition and antimicrobial activity of honeybee (Apis mellifera ligustica) propolis from subtropical eastern Australia. The Science of Nature. $2015 ; 102(68): 1-11$

33. Andrews JM.; Andrews. Determination of minimum inhibitory concentrations Journal of Antimicrobial Chemotherapy. 2001; 48(1): 5-16.

34. Turnidge JD, Ferraro MJ, Jorgen JH. Susceptibility test methods: General considerations. Manual of Clinical. Microbiol. 2003; 8: 219223.
35. Sambrook J, Russel DW. Molecular cloning, a Laboratory Manual, $3^{\text {rd }}$ edition. Cold Spring Harbor, NY: Cold Spring Harbor Laboratory. 2001.

36. Collins et a.l, Collins CH, Lynes PM, Grange JM. Microbiological Methods $\left(7^{\text {th }}\right.$ edition). Butter wont-Heinemann Ltd, Britian. 1995; $\mathrm{p}$ 175-190.

37. Farouk AE, Benafri A. Antibacterial activity of Eurycoma longifolia Jack. A Malaysian medicinal plant. Saudi Med. J. 2007; 28: 1422-1424.

38. Farouk A, Ghouse, FA, Ridzwan BH. New bacterial species isolated from Malaysian sea cucumbers with optimized secreted antibacterial activity. Am. J. Biochem. Biotechnol. 2007; 3(2) : 60-65.

39. Barret J, Bernnan J, Moran N and Patton T. Use of a spectrometric bioassay for determination of microbial sensitivity to Manuka honey. Journal of Microbiological Methods. 2006; 64(1): 84-95.

40. Al-Waili NS. Topical honey applications vs. Acyclovir for the treatment of recurrent Herpes simplex lesions. Diagnosis and Medical Technology. 2004; 10(8): MT94-MT98.

\section{How to cite this article:}

Farouk AE, Ahamed NT, AlZahrani O, Alghamdi A, Bahobail AA. Inducible Antimicrobial Compounds (Halal) Production in Honey Bee Larvae (Apis mellifera) from Rumaida, Taif by injecting of various dead Microorganisms extracts. J App Biol Biotech. 2017; 5 (02): 023-029. DOI: 10.7324/JABB.2017.50204 